\title{
Career Path Under the Lens: From Technician to Technical Specialist
}

\section{KD Derr}

\section{Carl Zeiss Research Microscopy Solutions, San DIego, California, United States}

Choosing to enter the Electron Microscopy Associate's Degree Program at Madison Area Technical College (MATC) was a practical rather than a passion filled decision. If I was going to take a student loan, I demanded a skillset that would allow me to pay it back as quickly as possible. The MATC degree catalog stated that $100 \%$ of the students in the Electron Microscopy (EM) program were working in their field of study. This was a much more attractive proposition than my top pick 'Graphic Design' had to offer with their two year waitlist and less than 50\% employment stats. So, I made what felt like a choice-less choice and enrolled in the Electron Microscopy Program. I honestly had no idea what I had signed myself up for.

After completing my degree, it took me a few years of bumbling around professionally to find my footing. When I landed at the New York Structural Biology Center (NYSBC), I discovered my passion for automation and contributing to the technical aspects of microcopy. I found that I had little interest in what we were looking at in the microscope. Instead, I focused on pushing the boundaries of what can be done with electron microscopes and the sample preparation techniques.

NYSBC changed my trajectory. It was the first microscopy job that took interest in developing my skills and professional network. I was encouraged by the NY Structural Biology Community to complete a Bachelor's Degree to lay the groundwork for a PhD. Since I was a working scientist, I elected to swing out and get a bachelor of fine art with an emphasis on sculpture. This fed my creative side, which contributed to innovative problem solving at the lab. The fine motor skills I had developed for ultramicrotomy was directly applicable to producing the perfect patina on my pieces. My understanding of phase diagrams provided insights that resulted in shortcuts and novel uses of materials. I won awards for novel textile design. For me art and science became interchangeable with the emphasis on creative thinking in both fields.

After completing my bachelor's degree, I looked more seriously at getting a PhD. Once again, I made a practical decision and decided that I was not willing to take a pay cut while I completed schooling and multiple post-doctoral fellowships. Looking at the state of scientific funding in the US, I was not sure that I would ever be able to find faculty position much less recover from that lost wages and retire above the poverty level. At that time, I was convinced that I had hit the glass ceiling and I left my position at NYSBC to start a Marketing Company.

This is where I learned the depth of connections within the EM community. Once it was known I was a free agent, it did not take long for my phone to start ringing and my email box to fill up. Before I knew it I had no time to spend working for my Marketing Company. The Electron Microscopy Community was not ready for me to leave it behind. I was offered an Adjunct Position at Hunter College and The CUNY Graduate Center. I spent a few days a week with Lee Cohen-Gould and at Weill Cornell Medical College. And Myrna Parkin from M.D. Parkin and Associates taught me how to break through the glass ceiling.

I have been an Electron Microscopy Specialist, the technical expert on the sales team, with ZEISS for more than seven years now. Every day I get to apply my technical EM skills to solve real scientific problems across a broad range of scientific disciplines. I have a much bigger impact on technology development at ZEISS, than would have ever been possible if I stayed in academic research and received a $\mathrm{PhD}$. 
Looking back choosing Electron Microscopy was one of my better life decisions. I have a rich network of friends and colleagues with diverse backgrounds. I have had the opportunity to live and work all over the world. I was able to complete a bachelor's degree in Fine Art. And my student loans have been paid off for over a decade. Not bad for a farm girl from the Midwest. I would choose electron microscopy all over again. 